\title{
Renewed Interest in Herbal Drugs Research
}

\section{Bello Hassan Onimisi}

Department of Medicinal Chemistry and Pharmaceutical Chemistry, Olabaisi Onabanjo University, Sagam, Ogun State Nigeria

*Corresponding Author: Bello Hassan Onimisi, Department of Medicinal Chemistry and Pharmaceutical Chemistry, Olabaisi Onabanjo University, Sagam, Ogun State Nigeria.

Received: June 21, 2019; Published: July 05, 2019

DOI: $10.31080 /$ ASPS.2019.03.0330

Orthodox medicine has been playing a big role in the health care of the people for a long time. This is because it has a lot of advantages over herbal medicine in terms of dosage regiment regulations, easy study of mode of action and mechanism of action. With orthodox medicine, many diseases has been cured and others have a bright chance of been cured as research into drugs is advancing day in day out. The advent of high technology especially in the areas of NMR, IR etc has open a new vista of hope for more drugs to be discovered in the near future.

On the other hand, the high poverty index in developing nations especially in Africa has cause a shift from orthodox drugs to herbal dugs.

It has been said that an average African lives on less than two dollars a day. Where will they get the money to purchase the dugs whose price is increasing every day?
Hence herbal dugs is the new alternative some developing countries for a long time has allowed this to un side by side with orthodox drugs.in Africa especially Nigeria government is just giving recognition to herbal medicine in addition, some universities in the country have commence a degree programme in herbal medicine. This is a boost to the new frontier in pharmacy and health care delivery.

\section{Volume 3 Issue 8 August 2019 \\ (C) All rights are reserved by Bello Hassan Onimisi.}

